\title{
Seroprevalence of Brucellosis in Sheep and Cow Herds of Kermanshah Province by Conventional Methods during the Period 2008 to 2013
}

\author{
Saeed Salari', Mehrdad Pooyanmehr², Ahmad Rashki', Shaghayegh Peykani' \\ ${ }^{1}$ Department of Pathobiolgy, Faculty of Veterinary Medicine, University of Zabol, Zabol, Iran \\ ${ }^{2}$ Department of Pathobiology, School of Veterinary Medicine, Razi University, Kermanshah, Iran \\ Email: saeedsalari@ut.ac.ir, mehrdad.poyan20@gmail.com, ah rashki@usal.es, ps.shaghayegh71@gmail.com
}

Received 16 October 2015; accepted 1 November 2015; published 10 November 2015

Copyright (C) 2015 by authors and OALib.

This work is licensed under the Creative Commons Attribution International License (CC BY).

http://creativecommons.org/licenses/by/4.0/

(c) (i) Open Access

\begin{abstract}
Aim: Brucellosis, as a zoonotic disease, is characterized by reduced fertility in animals. This study has aimed to assess the prevalence of brucellosis in sheep and cows rearing in Kermanshah Province. Methodology and Results: The study was conducted in the regions of Kermanshah whereas people had seropositive results for brucellosis. Serum samples of sheep and cow flocks were screened using tow conventional methods. The sheep was the most ruminant infected with brucella. The most seropositive cases were found in the year 2011. Conclusion, Significance and Impact of Study: Control and eradication programs among animals should be regarded as a priority measures in prevention of human brucellosis. The zoonotic aspects of brucellosis must be considered. When the disease exists in animals, especially in ovine and caprine, it is a concern for human public health. In order to control this zoonotic disease, close cooperation of health and veterinary organizations is necessary.
\end{abstract}

Keywords

Brucellosis, Cow, Conventional Methods, Kermanshah, Sheep

Subject Areas: Epidemiology, Immunology, Infectious Diseases

\section{Introduction}

Brucellosis is an important zoonotic disease of animals in which man is an accidental host [1]. The disease is particularly seen in the sheep, goats, cattle, buffalos, canine, other farm and wild animals; yet, wild animals are

How to cite this paper: Salari, S., Pooyanmehr, M., Rashki, A. and Peykani, S. (2015) Seroprevalence of Brucellosis in Sheep and Cow Herds of Kermanshah Province by Conventional Methods during the Period 2008 to 2013. Open Access Library Journal, 2: e2039. http://dx.doi.org/10.4236/oalib.1102039 
reported to be the reservoir for the domestic animals. The species of Brucella and their principal farm animal hosts are Brucella abortus (cattle), Brucella mellitensis (goats), Brucella suis (pigs), B. canis (dogs), Brucella ovis (sheep) and B. neotoma (rat). Only B. melitensis is the most important agent responsible for this zoonotic disease [2]. This bacterium is a gram negative, non-motile, small cocobacilli which has aerobic metabolism [3]. It has a worldwide distribution and most countries have attempted to provide the resource to eradicate the disease from the domestic animal population, especially in Mediterranean countries and the Middle East and it remains a significant public health concern [1]. Although brucellosis and its means of transmission were discovered over 100 years ago but it is still a serious disease problem facing the veterinary and medical professions due to economic losses to the livestock industry in infected areas resulting from reproductive failure such as abortion or birth unthrifty in the female, orchitis, epididymitis with frequent sterility in the male, decreased milk production and the cost of culling and replacement animals [4]. Additional losses result from human infection (Undulant fever or Malta fever) including debility and generalized aching, which may last for months or years [5]. In human, consumption food and occupational contact are the major risks of infection, traditional eating habits including the consumption of unpasteurized milk and fresh cheese and butter, is particularly common in the rural areas. These products are the primary causes of the spread of brucellosis. Brucellosis could be counted as an occupational risk for farmers, shepherds, butchers, laboratory worker and veterinarians because the disease, as a result of contact with infected animals or their products, could be entered or transmitted through inhalation of contaminated aerosols and also contact with conjunctival mucosa, or cuts and abrasions in the skin [6]. Since brucellosis eradication programs, in Iran, are based on vaccination, test, slaughter and quarantine as control measures, it is essential to distinguish the prevalence of the diseases among the animals. Therefore, this study was performed as a cross sectional survey to uncover the prevalence of brucellosis in sheep and cow herds of the Kermanshah Province of Iran.

\section{Materials and Methods}

As a descriptive cross sectional survey, between years 2008 and 2013, a total of industrial and semi-industrial husbandry of sheep and cow were screened to determine the seroprevalence of brucellosis. About 12,000 cows were monitored every year while the sheep flocks (average 1000 sheep per year) were surveyed according to the regional focus. The survey was carried out in Kermanshah province of Iran, where the people who lived in near areas of farms, had the history of positive result of brucellosis test, reported by the ministry of health.

Blood Sample Collection: Regarding to the comments of Animal Ethics Committees, about $10 \mathrm{ml}$ of blood was collected from jugular vein of each selected ruminant in to plain vacutainer tube and allowed to clot in a slant position at room temperature and the serum was decanted in to a labeled vial and stored at $-20^{\circ} \mathrm{C}$ until tested [7].

Rose Bengal Plate Test (RBPT): All serum were tested for Brucella genus using slide agglutination by RBPT (Pasteur Institute of Iran, Tehran, Iran) as per the procedure described in Alton et al. [7] and OIE Manual [8]. One drop $(0.03 \mathrm{ml})$ of serum was taken on a glass slide by micropipette. The antigen bottle was shaken well to ensure homogenous suspension and then one drop $(0.03 \mathrm{ml})$ of rose bengal antigen was added. The antigen and serum were mixed thoroughly with the spreader and then the slide was rotated for four minutes. The result was read immediately after four minutes.

Standard Tube Agglutination Test (STAT): STAT followed by 2-mercaptoethanol (Pasteur Institute of Iran, Tehran, Iran) were applied just for cow's serum, to detect antibodies against B. abortus strain. Serums of blood samples have been taken; dilutions of blood serums have been prepared as 1:10, 1:20, 1:40, 1:80, 1:160 and $>1: 160$. Then, $0.5 \mathrm{~mL}$ of Brucella tube test antigen (Pasteur Institute of Iran, Tehran, Iran) for each reaction has been added. The tubes have been incubated at $37^{\circ} \mathrm{C}$ for 24 hours. Agglutination in 1:40 and above dilutions in serum antigen mixtures has been evaluated as positive.

Statistical Analyses: Descriptive statistics such as frequency and percentage were used to analyze the data using Statistical Package for Social Sciences. Chi-square and ANOVA tests were used to determine the significance of difference observed between two different groups. P values $<0.05$ were considered statistically significant.

\section{Results}

From the total of blood samples, 6 samples of cows were positive for brucellosis in 2008. In this year, the sheep 
were not sampled. The most seropositive cases were found at year 2011 ( 5 cases for cows and 306 cases for sheep). 6, 5, 0 and 2 cases of cows were positive in year 2010, 2011, 2012 and 2013, respectively while in these years, 12, 306, 25 and 0 cases were subjected as seropositive sheep, respectively. The sheep was the most ruminant infected with brucella (Table 1).

\section{Discussion}

In most developing countries, brucellosis is still an endemic disease in human and animals, so in order to control and eradicate the disease [9], it is very important to establish appropriate serological methods which depend on the use of two or more tests and then use more specific test to confirm any positive cases [10]. Although the seroprevalence of brucellosis in various animals has been described in Iran, there is many inquiries about human brucellosis in the region. There are many reports investigated the prevalence of brucellosis [11] [12]. As a first time, in the present study, we investigated the prevalence of brucellosis in ruminants housed in Kermanshah province of Iran for six years to increase the understanding of public health importance of this zoonotic disease. Our result are in line with the investigation of Ahmadieh et al. that reported the rate of infection was higher in sheep and goats than cattle during 1997-2001 in Kordestan Province [13] [14]. According to study conducted by Faiuzi in 2007 in Golestan Province, the rate of infection of cows were 1.62\% in industrial and $0.55 \%$ in native cows while in the present study the rate of infection was nearly close [15]. Our samples were collected from husbandries nearby the area where reported by the Ministry of Health and Medical Education of Iran that had the history of positive result of human brucellosis test. The seroprevalence of brucellosis in racing clubs and private horse owners in the south of Iran and risk factors associated with the disease in horses were determined [16]. The results showed that most seropositive horses in this study were asymptomatic. There is a little study about human brucellosis in Kermanshah. Hamzavi et al., investigated some epidemiological characteristics of brucellosis in all patients with brucellosis submitted to health centers of Kermanshah province, through 2011. Consumption of unpasteurized milk has been found as main route for infection in patients. Their results, also, showed the high prevalence of brucellosis in special rural areas such as Daalaahoo and Sarpole Zahab and finally, they recommended to prepare educational strategies about the disease [17]. In another study during 2008 to 2009 on native and industrial cows and also sheep of Mazandaran Province, 1863 cows including 679 (36.44\%) industrial and 1184 (63.56\%) native and 1469 sheep were examined. From the total 1863 examined cows, 94 (5.04\%) were positive including 22 (23.4\%) industrial and 72 (76.6\%) native cows. Also from 1469 sheep studied 358 (24.37\%) were infected with this agent [18]. Unfortunately, the type of husbandry in our research was not documented. As we mentioned in results, between 2008 and 2013, the most ruminant population which infected with brucella were the sheep. Also, the most seropositive cases were found at year 2011. Course of the disease, local conditions, rate of exposure to infection related to movement could be the explanation for the higher rate of infection in sheep. Because the sheep flocks are more motile than cow herds, they can expose to the agent more than cow. Also the improper management of pregnant ewe could play an important role to spread of infection. These finding showed broad contaminations of domesticated animals which could be of great important regarding hygiene of human societies. Brucellosis is a significant public health problem all around the world and specially Iran, could be limited and eradicated by close control of the animals. Not only breeders but also consumers of animal products are at risk. Hence, pasteurized milk should be consumed and used in the production of dairy products. The results of our investigations indicate that control and eradication programs among animals should be regarded as a priority measures in prevention of brucellosis.

Table 1. Distribution of the prevalence of brucellosis in Kermanshah Province (2008-2013).

\begin{tabular}{|c|c|c|c|c|c|c|c|c|c|c|c|c|c|}
\hline \multirow{3}{*}{$\begin{array}{l}\text { Species of } \\
\text { animal }\end{array}$} & \multicolumn{2}{|c|}{2008} & \multicolumn{2}{|c|}{2009} & \multicolumn{2}{|c|}{2010} & \multicolumn{2}{|c|}{2011} & \multicolumn{2}{|c|}{2012} & \multicolumn{2}{|c|}{2013} & \multirow{3}{*}{$\begin{array}{c}\text { Total } \\
\text { positive } \\
\text { case } \\
\text { (No.) }\end{array}$} \\
\hline & \multicolumn{2}{|c|}{ Positive cases } & \multicolumn{2}{|c|}{ Positive cases } & \multicolumn{2}{|c|}{ Positive cases } & \multicolumn{2}{|c|}{ Positive cases } & \multicolumn{2}{|c|}{ Positive cases } & \multicolumn{2}{|c|}{ Positive cases } & \\
\hline & No. & $\%$ & No. & $\%$ & No. & $\%$ & No. & $\%$ & No. & $\%$ & No. & $\%$ & \\
\hline Cattle $^{+}$ & 6 & 0.05 & 2 & 0.01 & 6 & 0.05 & 5 & 0.04 & 0 & 0 & 2 & 0.01 & $21^{*}$ \\
\hline Sheep $^{++}$ & ND & ND & 229 & 22.9 & 12 & 1.2 & 306 & 30.6 & 25 & 2.5 & 0 & 0 & $572^{*}$ \\
\hline
\end{tabular}

${ }^{+}$Total number of investigated animal/year = 1000; ND: No Data; ${ }^{*} \mathrm{P}<0.05$. 


\section{Conclusion}

According to the high rate of infection in sheep and the high demand for rearing of this animal in Kermanshah Province, the zoonotic aspects of brucellosis from animals must, therefore, be considered because the disease is important from the public health standpoint. When the disease exists in animals, which is a reservoir, it is a concern for human public health. In order to control this zoonotic disease, close cooperation of health and veterinary organizations is necessary to design proper programs and lectures for knowledge increase about brucellosis in farmers.

\section{References}

[1] Krkić-Dautović, S., Mehanić, S., Ferhatović, M. and Cavaljuga, S. (2006) Brucellosis Epidemiological and Clinical Aspects (Is Brucellosis a Major Public Health Problem in Bosnia and Herzegovina?). Bosnian Journal of Basic Medical Sciences, 6, 11-15.

[2] Sabbaghian, H. (2002) Control of Infectious Diseases in Human. Ebnesina Press, Tehran, 99-103.

[3] Joafshani, M.A., Zoghi, E. and Simani, S. (2005) Zoonotic Disease in Iran. Tehran Academic Press, Tehran, 11-23.

[4] Montasser, A.M., Hamoda, M.F.K. and Talaat, A.S.H. (2002) Some Epidemiological and Diagnostic Studies on Brucellosis among Ruminants in Kafer-El-Sheikh Governorate. Journal of Egyptian Veterinary Medical Association, 62, 25-38.

[5] Arda, M., Minbay, A., Leloglu, N., Aydin, N., Kahraman, M., Akay, O., Ilgaz, A., Izgur, M. and Diker, K.S. (1997) Special Microbiology-Epidemiology: Bacterial and Mycotic Infections. Medisan Publication, Ankara, 197-223.

[6] Mukhtar, F. (2010) Brucellosis in a High Risk Occupational Group: Seroprevalence and Analysis of Risk Factors. Journal of Pakistan Medical Association, 60, 1031-1034.

[7] Alton, G.C., Jones, L.M. and Pietz, D.E. (1975) Laboratory Techniques in Brucellosis. World Health Organization, Geneva, 55.

[8] World Organization for Animal Health (OIE) (2012) Bovine Brucellosis. In: Vallat, B. and Caporale, V., Eds., Manual of Diagnostic Tests and Vaccines for Terrestrial Animals (Mammals, Birds and Bees), OIE, World Organization for Animal Health Press, Geneva, 616-651.

[9] Radostits, O.M., Gay, C.C., Hinchcliff, K.W. and Constable, P.D. (2007) Diseases Associated with Brucella Species. In: Renhuis, J., Ed., Veterinary Medicine (A Textbook of the Diseases of Cattle, Horses, Sheep, Pigs and Goats), Elsevier, Saunders, Edinburgh, 963-994.

[10] Zowghi, E. (1990) Microbiology of Brucella. Agricultural and Natural Resources Research Center Press, Tehran, 312-329.

[11] Hunduma, D. and Ragasa, C. (2009) Seroprevalence Study of Bovine Brucellosis in Pastoral and Agro Pastoral Areas of East Showa Zone, Oromia Regional State, Ethiopia. American-Eurasia Journal of Agriculture and Environmental Science, 6, 508-512.

[12] Ali, F.H.M. and Mahdey, E.A. (2010) Incidence of Brucella Species in Slaughtered Food Animals and Its Edible Offal at Beni-Suef, Egypt. Global Veterinaria, 5, 248-254.

[13] Ahmadieh, M.M. and Dehghani, M.H. (2002) Study of Data in Patient Files in Nikoo Puriazdi Health Center. Global Veterinaria, 8, 194-200.

[14] Nicoletti, P. (1980) The Epidemiology of Bovine Brucellosis. Advances in Veterinary Science and Comparative Medicine, 24, 69-98.

[15] Al-Majali, A.M. (2009) Seroprevalence and Risk Factors for Bovine Brucellosis in Jordan. Journal of Veterinary Science, 10, 61-65. http://dx.doi.org/10.4142/jvs.2009.10.1.61

[16] Badiei, K., Sharifiyazdi, H., Pourjafar, M., Ghane, M. and Hashemi, S.A.N. (2013) Seroepidemiology and Molecular Detection of Brucella Infection in Iranian Horses: A Provincial Study. Iranian Journal of Veterinary Medicine, 7, 4349.

[17] Hamzavi, Y., Khademi, N., Ghazizadeh, M.M. and Janbakhsh, A. (2014) Epidemiologic Survey of Malt Fever in Kermanshah Province through 2011. Journal of Kermanshah University of Medical Science, 18, 114-121.

[18] Esfandiary, B., Lesan, Sh., Youssefi, M.R. and Abouhosseini Tabari, M. (2010) Studies on the Prevalence of Brucellosis in Domesticated Animals during 2008 to 2009 at Mazandaran Province, Iran. Global Veterinaria, 5, 106-108. 